\title{
Creating Coordinative Paths from admission to discharge: The role of lightweight IT in hospital digital process innovation
}

\author{
Egil $\emptyset_{\text {vrelid }}$ \\ University of Oslo \\ egilov@ifi.uio.no
}

\author{
Terje Aksel Sanner \\ University of Oslo \\ tsanner@gmail.com
}

\author{
Anette Siebenherz \\ Østfold Hospital \\ Anette.Siebenherz@so-hf.no
}

\begin{abstract}
In this paper, we examine the role of IT in process innovations related to patient flow from emergency care admission, through subsequent patient transfers, and discharge. In particular, we explore how digital technology helps create and improve coordinative paths. We find that the interplay between traditional "heavyweight IT" (resilient, secure and stable) and "lightweight IT" (mobile, context-aware and flexible) enable process innovation in complex health care settings. Drawing on Zuboffs "informate" perspective, we highlight the strength of digital information technology as a process innovation enabler. We provide two contributions. First, we shed light on the innovative capacity of lightweight IT as a flexible, dynamic and distributed technology for process innovation. Second, using Garud and Kumaraswamys framework of vicious and virtuous circles, we identify and discuss potential positive and negative outcomes of process innovation.
\end{abstract}

\section{Introduction}

General hospitals are structured to optimize specialists and departments vertical work processes, while horizontal coordination have received less priority. This clinical orientation is mainly caused by interdependencies related to specialization [2]. A challenge with this form of organization is that patients who suffer from ill-defined or interrelated health issues are referred back and forth between seemingly uncoordinated professionals and departments for diagnosis and treatment. A common complaint from patients is thus that while the actual treatment was excellent, the coordination between units was slow, the waiting time long, and feedback almost nonexistent [3, 4]. In Norway, these challenges have informed the establishment of national coordination reforms, as it is "particularly important to ensure good coordination when the responsibility for the patient moves between hospitals and municipalities and between departments and units within hospitals and municipalities" [5].

Davenport [6:8] claims that "in functionally oriented organizations, handoff between functions are frequently uncoordinated." Process innovation improve coordination and management of functional interdependencies [6]. Nevertheless, initiatives striving for improved horizontal processes through better clinical pathways or other ways of appropriating the patient trajectory using IT, have had limited success [7]. Substantial improvements may require optimization through digitalization and process redesign. This is important within hospital settings as reduction of time spent on logistics may release time for patient treatment $[9,10,11]$.

In accordance with [8] we refer to robust hospital information "silos" and the IT engineering and support tradition that envelops them as "heavyweight IT". However, to be able to leverage rapid developments in todays' IT industry and meet citizens growing expectations towards digitalized health care services, hospitals and other health care institutions strive to implement "lightweight IT" solutions, characterized by rapid implementation cycles, and ubiquitous access to tailored information through user-friendly interfaces [8].

In this paper, our goal is an improved understanding of process innovation and digitalization challenges in a hospital setting. We investigate efforts in digitalization of horizontal processes, our research question is what are the challenges and the outcomes of using lightweight technology in process innovation initiatives at a general hospital?

We proceed by discussing related research (2.1), before we describe our theoretical lens (2.2).

\section{Theory}

\subsection{Digital infrastructures and lightweight IT}

Public sector IT systems may be characterized as "IT silos", where data and functions are organized in a way 
that hampers innovation $[12,13]$. In addition, heterogeneous IT solutions deep embeddedness in clinical practices makes change challenging. In essence, the inertia of extant solutions and practices "resists" external intervention, and changes need to be introduced in small and incremental steps [14].

Hospital IT portfolios typically constitute fragmented and clinically oriented IT acquisitions. A long tradition of clinical orientation in the development of hospital IT portfolios have led to fragmented systems, support functions and regulations, which makes information exchange across departments difficult, even within the same hospital. This is of concern to hospital administrators as workflows that are more efficient can save costs, enhance efficient use of scarce hospital resources (e.g., radiology), lead to more effective diagnosis and treatment of patients, and reduce patient waiting time [15].

The conservative influence of extant hospital IT portfolios have for some time been challenged by process innovation initiatives seeking to create coordinative paths in order to improve horizontal performance. Examples are patient logistics [7], clinical pathways [17], and hospital supply chain management which is a systemic view of the flow of all types of resources [18]. These initiatives typically address "horizontal" workflow processes, but often fail to interact with and leverage existing databases and functions.

Digital process innovation is about using IT to improve business processes [6]. In the health sector, process innovation may refer to reducing the time spent between diagnoses, to treatment and followed up. In hospitals, this may be achieved by reducing waiting time and shortening the time from admission to discharge. Recently, we have seen a growth in digital services in tandem with individuals and organizations rapid uptake of commercially available devices such as tablets, smartphones, wearable sensors and electronic whiteboards. [8] refer to this as "lightweight IT". Lightweight IT is not only a tool, but also "a sociotechnical knowledge regime, driven by competent users' need for solutions, enabled by the consumerization of digital technology, and realized through innovation processes" [8:2].

We employ the notion of lightweight IT based on three characteristics. First, we are particularly interested in the role of lightweight IT as a front-end knowledge regime driven by practice-oriented innovation. We primarily study practices related to coordinative activities and the innovation of coordinative processes. We are also interested in the role of heavyweight IT in supporting lightweight IT, especially because it is through interplay between lightweight and heavyweight that favorable results are likely to be obtained [8]. The two knowledge regimes should be loosely coupled both technically, regarding standards and organizationally [8]. Second, even though we strongly acknowledges the important role of heavyweight IT in feeding lightweight IT with information, we particularly investigate the role of whiteboards and mobile technology in sharing, visualize, and redistribute information. This informating ability is contributing to transparency and improved overview in a way that may enable bottom-up and locally relevant process innovation. Third, we are interested in lightweight IT as an example of digital innovation. This includes investigating the innovative potential including the increasing redesign flexibility [23]; their ability to establish digital links and provide changed control paradigms [20], through distributed organization [21].

In summary, the innovation of coordinative processes is facilitated by using mobile technology and whiteboard technology, that is, lightweight IT, characterized by rapid implementation cycles, and ubiquitous access to tailored information through userfriendly interfaces. The whiteboards also facilitates the inspection of the result of process innovation in that information is displayed in common arenas where patient flow is discussed. The redesign flexibility, we claim, is both helpful in establishing digital links, but also in providing distributed autonomy.

For instance, [25] have studied the interplay between lightweight and heavyweight IT in process innovation, but mainly from a strategical perspective. Our study, on the other hand relates to the practical implications of this interplay, how lightweight and heavyweight IT interaction supports "everyday" coordination within and across organizational departments and functions.

Lightweight IT solutions have recently shown promising in supporting cross-functional processes in complex settings, for instance by improving organizational visibility of treatment statuses $[9,26,28]$ as well as patient coordination care [29]. These studies primary focus, however, is improved coordination within a particular department. In this paper, we rather focus on initiatives related to improving horizontal workflows across departments as well as the challenges related to these innovation activities.

\subsection{Process innovation and its challenges}

Process innovation is about translating information into action by removing manual work between the source and the registration [30]. This can be done through better coordination and management of functional interdependencies [6]. Drawing on Zuboffs [31] notion informate, we denote the process of leveraging IT to make information about work visible and actionable across organizational functions and departments. Zuboffs informating framework indicates the need for 
management to be active in recognizing IT's potential to generate information about the underlying productive and administrative processes that were previously opaque. Zuboff documents how the explicit representation of tasks, gathered from monitoring agent behavior and/or outcomes, sets in motion a series of dynamics that will ultimately (re)configure the nature of work and social relationships that organize productive activity. In essence, Zuboff observes that informating will improve performance and the quality and autonomy of working life, when employees are obligated, and accept, the use of feedback from IT to adjust their work behavior.

Informate, then, is a condition enabled through digitalization and automation of manual processes or through compiling digital processes or information earlier displayed separately. Digitalization of processes, what Garud and Karnøe [32] calls path creation, may entail struggling against existing social rules and taken for granted techniques and tools. In a way, entrepreneurial activity is about disembedding oneself from existing structures and mobilize support, rather than resistance from an inertia of work practices and systems. Hence, process innovation "is a collective effort where paths are continually and progressively modified as new technological fields emerge" [32:2].

Informate can both be a result of complex interacting processes i.e. integrated modules, and local resources made universal through enabling access across organizational units. Digital interconnectedness enables improvement of horizontal performance but it also threatens stabilized local processes and departments [23]. The increasingly sophisticated insight into patterns of organizational processes and information may tempt managers to disturb complex and interdependent processes [33]. Furthermore, the use of the information potential enables a better overview of the positive and negative effects of process innovation. In turn, this may inspire strategies to reinforce and sustain virtuous circles [1]. However, the coupling of different organizational processes can give rise to unanticipated negative consequences that may degenerate into vicious circles [34]. Two principles are suggested by [32, 34] to avoid vicious circles. First, avoid tight coupling between system components as it may cause feedback generated at another level or in another system to amplify across the entire system and generate unintended negative consequences [34, 1]. A second example is the negative result of increased bureaucracy and centralization of decision making [34].

The information system and its dynamics can thus be outlined in three properties. First, the effects of initiatives taken at one level of the system can be felt across the levels. Second, these effects may lead back to the mutually causal nature of processes unfolding at and across levels, and third, the effects of specific initiatives are not immediately obvious because of time lags between causes and consequences. There is therefore an inherent ambivalence in the dynamics. If you leave the information system alone virtuous circles may never materialize. If you intervene and connect or couple processes within and across levels and functions vicious circles may emerge [1].

In order to steer out of vicious circles one should identify and decouple system processes that may have triggered the vicious circle, or establish a deviation counteracting tool. This could be middleware or other forms of automated tools which counteract the negative impact of process innovation [1]. This careful navigation enabled by organizations informating ability is interesting on two grounds. First, we investigate the role of lightweight technology in process innovation. Second we investigate how process innovation initiatives leads to vicious or virtuous circles, and how lightweight IT supported by heavyweight IT is used to identify, disseminate and adjust outcomes.

\section{Method}

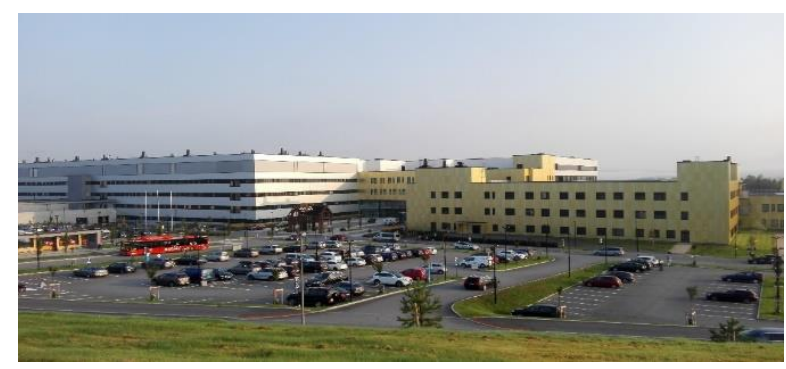

Figure 1: Kalnes Hospital

The setting for our empirical research is Kalnes general hospital in Østfold County (near Oslo) in Norway. Østfold has about 300.000 inhabitants. The 85.500 square meter high-tech hospital opened in November 2015 and replaced the old Fredrikstad hospital. Kalnes has one of Norway's largest emergency units in addition to general hospital functions such as delivery wards, clinical and surgical departments and psychiatry. At the old hospital in Fredrikstad, departments were distributed across different buildings with up to nine floors based on functional separation. At Kalnes the hospital design is markedly different. The hospital has four floors that provide health services and the building was designed to allow different departments to dynamically expand and retract. The construction of Kalnes hospital has created opportunities for hospital-wide process innovation. Mobile technology and electronic whiteboards are deployed all over the hospital. The electronic whiteboards provide up to date information for patients, their families, professionals assigned to patients and hospital support staff. The hospital management has 
high ambitions regarding its process-oriented use of IT [25]. Kalnes Hospital serves as an extreme case of our area of concern [35], because of the ambitious efforts to integrate and align clinical work processes and patient records keeping with novel innovative technology to support horizontal process innovation and coordination.

Our case study research approach is based on engaged scholarship [16, 19] inspired by an "insiders ontology" [22] where informants are not only sources of empirical data, but also helpful in constructing narratives and discuss theoretical and practical implications [16]. One of the authors of this paper was central in the process of planning and implementing the IT solutions at Kalnes. The planning included redesign of the old workflow processes at Fredrikstad, as well as organizational restructuring.

\subsection{Data collection}

From July 2016 to April 2017, we conducted 22 interviews, with clinicians, project leaders, technical experts and cleaning personnel as well as system suppliers. We started with interviews where Kalnes management and project leaders presented the main goals as well as the organizing of the IT oriented process innovation initiative. We proceeded by performing observations within the emergency unit and the health wards, where challenges related to process flow were addressed. We followed up with new interviews as well as analyses of documents on patient treatment regulations, political requirements from the regional health authorities and descriptions of the technical solutions. We also participated in local and regional meetings and workshops where findings, including ours, were discussed. Through this "bottom-upinvestigation", we identified coordinative actors, actors whose central role is to plan and coordinate the movement of patients and information across hospital departments, and were particularly interested in how they use IT to perform and coordinate their work.

\subsection{Data Analyses}

Our initial data analysis was informed by two themes: the identification of opportunities and challenges for assisting process oriented re-design of hospital patient flows with digital ICTs and the role of ICTs in mitigating emergent process bottlenecks. For instance, mobile and whiteboard technology availed information about the status of patients and resources such as rooms and beds across hospital functions in real time. However, this seamless information transparency could sometimes introduce new coordination challenges.
We analyzed the case in the light of how interplay between technological components enable or constrain work performance of coordinative actors, and were particularly interested in the challenges and possibilities that arise and how they were dealt with. We then used the conceptual model from [1] to analyze respectively the challenges and outcomes of innovate-informate interaction, before we discussed the implication for our findings on the field of research, and identified some contributions. Table 1 provides details of our analysis.

Table 1: Data analysis

\begin{tabular}{|l|l|}
\hline Questions-Description & Output \\
\hline $\begin{array}{l}\text { Identify key coordinative actors } \\
\text { and their challenges regarding } \\
\text { process flow, as well as the key } \\
\text { technology for supporting process } \\
\text { flow }\end{array}$ & $\begin{array}{l}\text { Case description, } \\
\text { three steps of } \\
\text { digitalization to } \\
\text { obtain process } \\
\text { innovation. }\end{array}$ \\
\hline $\begin{array}{l}\text { Follow key actors, key meetings } \\
\text { and clinical encounters in order to } \\
\text { identify situations where } \\
\text { digitalization initiatives improves } \\
\text { or challenges existing order and } \\
\text { the outcome of this. }\end{array}$ & \\
\hline $\begin{array}{l}\text { Identify core processes and } \\
\text { resources, the initiatives to } \\
\text { digitalize them, and the outcome. }\end{array}$ & \\
$\begin{array}{l}\text { For instance, when sharing the } \\
\text { status of resources faster and to } \\
\text { more relevant decision makers, } \\
\text { what challenges arise? How are the } \\
\text { possibilities and challenges dealt } \\
\text { with? }\end{array}$ & \\
\hline $\begin{array}{l}\text { Analyze the process innovation } \\
\text { challenges using the conceptual } \\
\text { model from [1] in order to } \\
\text { generalize our findings. }\end{array}$ & $\begin{array}{l}\text { Analyses, } \\
\text { digitalization in } \\
\text { the light of } \\
\text { challenges and } \\
\text { outcomes }\end{array}$ \\
\hline $\begin{array}{l}\text { Theorizing the challenges and } \\
\text { outcomes when using lightweight } \\
\text { technology in process innovation }\end{array}$ & $\begin{array}{l}\text { Two } \\
\text { contributions, } \\
\text { discussion. }\end{array}$ \\
\hline
\end{tabular}

\section{Case}

Kalnes emergency unit receive between 90 and 120 patients every day. Some arrive by helicopter or ambulance, but most patients "drop in" having been referred by their general practitioners or primary health care units. Kalnes hospitals efficiency goal for patient stay at the emergency unit is two hours, but the average time of stay is $4.5 \mathrm{hrs}$.

Kalnes hospital has several departments (e.g., neurology, heart and lung wards) positioned in close proximity to the emergency unit, where patients can stay for up to three nights. Each department has a coordinative nurse tasked with facilitating patient flow. Kalnes hospital fall under the jurisdiction of region Health South-East (HSØ), one of four semi-autonomous 
health regions in Norway with their own IT strategies and framework agreements. Kalnes hospital acquired standard electronic whiteboards and mobile devices with Imatis software installed as a part of their workflow-oriented design strategy. Imatis was previously implemented in the emergency unit at Køge hospital in Denmark through a cooperative project between the hospital staff, the vendor of the whiteboards and the University of Roskilde [26]. There is functionality in Imatis to display all available rooms in all departments and reserve them for patients. Hospital staff, regardless of function (e.g., nurse, clinician or housekeeper), can access custom Imatis views on mobile clients (tablets and smartphones) based on their role and location within the hospital. The Imatis vendor have had a close cooperation with Kalnes hospital both during implementation and in the activities related to improving and tailoring the solution according to Kalnes' needs. A project manager emphasize this: "It is very interesting to work with them...they are very active and interested in how we are doing." The EPR (Electronic Patient Records) provider does not ignore the creativity from Kalnes, but often respond with, "yes, this is a good idea, but you have to wait for our next upgrade." The internal project manager says, "Imatis recognizes that the development is happening here and now, not in 2 or 3 years."

A large portion of the information displayed through Imatis on mobile devices and whiteboards are harvested from the main EPR system at Kalnes. Imatis is also integrated with the personal administration system GAT. The interplay between the EPR, GAT and Imatis is central in enabling transparent information on the availability of hospital resources.

We investigated the role of electronic whiteboards and mobile technology and the clinical systems in patient flow coordination, following the coordinative actors, how they dealt with bottlenecks and flow challenges, and the role of IT as an important enabler in these endeavors.

We proceed by looking at the activities of digitalizing manual routines (4.1). Then we describe the improved transparency this gives (4.2) and how this overview may highlight solutions to challenges (4.3). Finally, we look at some particular challenges with digitalization efforts (4.4).

\subsection{Digitalizing processes and resources}

ICT has the ability to enable digital links and a more flexible interaction between organizational actors. An important activity related to digitalization is to divide entangled processes into sub processes measured separately. An example is triage. The purpose of triage is to ensure that patients with immediate needs for health care will receive it first. It is therefore important to separate the process of triage from the following treatment.

"Dividing processes and resources is a challenge. When clinicians are asked to measure the process of triage they perform and measure the entire treatment, not only the identification of what treatment is needed. While the process of triage takes around 2 minutes the treatment takes a long time, sometimes up to an hour."

The clinicians have the ability to quickly decide who needs treatment (tacit decision-making), and then complete the treatment. This could however lead to the most serious cases not be taken care of first. The logical separation of triage and treatment based on general principles (explicit decision-making) is an example of breaking more or less coherent vertical working processes into sub-processes measured separately.

Further, at the old hospital the coordination process of identifying available rooms and treatment resources was done manually, by walking around asking key personnel, and then make notes on the availability. At the new hospital, they have digitalized some of these resources. The digitalization enables the organization to share resources across local units and according to a universal standard. However, this may sometimes conflict with local autonomy and local rules for accessing and using the resources.

The digitalization of some of the cleaning routines have replaced a lot of the earlier ad-hoc communication that had to take place in order to secure good routines. The availability of resources through the mobile technology system enable the clinicians to notify when a room have to be cleaned and in what way by indicating airborne or body fluid contamination. Cleaners also make direct data entry into Imatis by indicating that they have "started cleaning" and "finished cleaning".

The most important aspect of patient treatment processes is to secure the quality and safety of care. The movement of a patient from the emergency unit to the health wards includes several quality checks performed and communicated between the receiver and the deliverer. An example demonstrates this.

First, the doctor assigned to the patient give the emergency unit coordinator the task of finding a room for the patient. The coordinator then registers in Imatis that the patient is "ready for ward". The receiving ward considers this request and responds. The status of the patient is updated to "reported to post". The coordinative nurse in the receiving ward identify a room for the patient and send a message to the hospital porter who makes sure that a bed is in place. Finally, a report about the patient transfer is sent from the emergency unit to the ward. "Our goal is a silent report, but some of these steps are still done manually by phone" (doctor). 
Fragmented healthcare portfolios require users to $\log$ in to a variety of systems. Also at Kalnes they have non-integrated systems where information is registered separately. By having these elements available in Imatis or the EPR further optimization of hospital performance and human and material resource utilization could be obtained. Kalnes have in collaboration with the major system providers of EPR and Imatis technology established an interface, which grants access to major information systems. This interface facilitates innovation, in that it gives access to information, which can be recombined across system domains.

\subsection{Informating: Transparency, visibility and collaborative arenas}

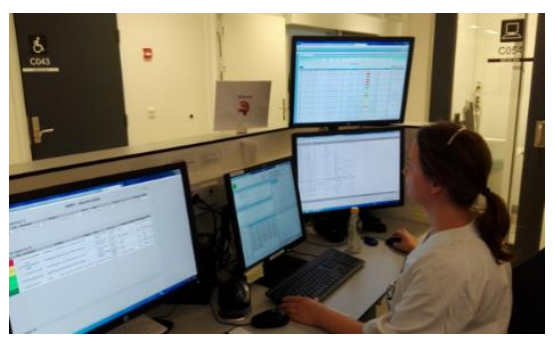

Figure 2: Emergency unit control board

The main admission point at Kalnes is well equipped with big screens displaying information from all the important systems (Figure 2). The whiteboard (upper right) first enables an overview of available resources, second it gives a fast and neat overview of the medical condition of the patient, the reason for the admission, the level of emergency (triage), the result of blood tests and x-ray results as well as the responsible nurse and doctor. Third, it enables an active participation in the dynamics of patient treatment information like registering patient, attaching necessary resources and switching care personnel when needed. The whiteboard keeps the clinical and logistical personnel informed about the status and enables a swift modification when needed. This functionality relies largely on the integration between whiteboards and the EPR systems.

The whiteboard system has introduced some improvements. "It's an important device in the administration of the unit... Earlier we had to call for every detail, now we have a much better overview" (nurse). In addition, communication with the cleaning personnel and the booking of beds is much easier thanks to Imatis. One nurse said, "It is much easier to get an overview when we have the information both in our heads and on the screens" (nurse). The health ward clinicians also emphasize the visual abilities of Imatis: "Imatis gives a good overview, also when family members call, it is easy to answer. It provides good communication with food makers and cleaners. In addition, it provides a good overview of patients admitted to the department and the department to which they belong."

The electronic whiteboard have enabled the creation of arenas for discussing the patient flow. Examples are the whiteboard morning meeting where the overarching focus is coordination and logistics. A central challenge at Kalnes is the peak at mid-day when both the emergency unit and the health wards are full. A solution to this challenge is to discharge patients from the ward in the morning so that the ward have availability in the mid-day when the emergency unit is full. The morning department meetings at the old hospital used manual whiteboards. Now they use electronic whiteboards.

"The whiteboard meeting starts at 0850, and lasts for ten minutes. In this meeting, all the admitted patients are discussed as they try to identify who can be discharged. The unit manager is managing the whiteboard registrations, while the doctors and nurses give feedback. The patients are divided into three categories: 1. immediate help, 2. Patients who can be discharged, 3. Patients who have to stay another day."

By enabling transparent information and use this information to optimize the process flow, whiteboard meetings is an important arena for process innovation. By touching the screen and changing status, decisions are registered immediately.

Through digitalization, making information visible and transparent, the cleaning personnel have the possibility to plan their daily performance. This is a nontrivial challenge made easier through enabling access to needed information for decision-making.

"Cleaners change the status of the resource; Cleaning in progress, Cleanliness finished." "The cleaning routines take approximately 30 minutes but sometimes it takes three hrs. from a room cleaning is booked to the cleaning is performed. This is especially in the "peak hours". The cleaners have rescheduled the way they work 4 times since the hospital was opened" (nurse).

The transparency and visibility provided by the digitalization of processes enables a local autonomy for the cleaning department to address and solve their main challenges themselves. More on this in 4.3.

\subsection{Self-management}

Process innovation obtained through digitalization gives improved transparency and provides an improved basis for decision-making on several grounds. First, digitalization provides easier access to information. Digitalization allows the information to be displayed in customized view, and this provides a basis for department/units self-management. Examples are the cleaners that can organize and re-organize their activities based on the actual hospital need. Another example are the ward managers who can organize their 
units based on analyzes of the daily patterns of referral, treatment and discharge. A third example are the coordinators that can identify the available and necessary resources and map them onto the patient trajectory.

Second, the whiteboards are both displaying information related to flow processes (when can the patient be discharged?), and information on specialized diagnostics and treatment. The whiteboard consequently bring together actors where some think about the flow while others think about clinical treatment. This strengthens the common insight into local challenges.

"In the patient visit, they use Imatis to identify who needs to be treated first, based on level of urgency. Then they work on the patients that most likely can be discharged the same day. This practice also enables the cleaning personnel to get a good insight into rooms which has to be cleaned so that they can do this right away."

The information visibility enables them to establish common arenas to address flow challenges. The whiteboard meetings are standardized ways of discussing patient flow, and recently a new type of meeting, "Patient flow seminars", was established by the process director to address more general challenges related to resource availability and process innovation.

The ICT potential is used actively to identify available resources, but also what it takes to define something as a (digital) resource. The access to crosssectional resources enables a proactive process where nurses and coordinators are checking availability when needed. The decentralized autonomy, discussions and negotiations is giving the departments increased understanding of the importance of process flow, and what it takes to optimize it. The visibility enables improved management based on the movement of resources across different wards, and a more flexible use of the workforce by assigning human resources to different units and tasks depending on demand.

\subsection{Process innovation challenges}

Process innovation through digitalization may create unintended effects or bring to life hidden challenges. An example is when universal resource transparency creates tension between local and global resource management:

"..The emergency unit applies to transfer a patient to the heart ward. The coordinator finds that the heart ward is full, but that they have two patients that can be transferred to the lung ward. The heart ward coordinator calls the lung ward which responds by saying that they have no available beds, but they do not report this back to the emergency. Patient is still marked "grey" in Imatis. 5 hrs after the first referral, the emergency calls back to the Heart Ward, only receiving the response that neither them nor lung has available beds. The patient coordinator nevertheless knows that the lung ward have space in the corridor. The emergency unit continues by enforcing the move of patients from heart to lung and then transferring the emergency unit patient to the heart ward 6 hrs. after the first inquiry."

The tight integration also gives challenges in terms of keeping users informed about where data actually resides and how information is shared and updated between systems. This may be particularly problematic when systems are so well integrated that end users no longer are able to assess what system they are making data capture against or retrieving information from - as everything is seamlessly "at their fingertips" in one user interface. For instance, as indicated by one housekeeper:

"Some coordinative nurses delay the booking of room cleaning for patients who are targeted for transfer or discharge as they are worried information registered in Imatis will feed back into the EPR where the status of the patient has not yet been updated by the clinician in charge of the patient".

In addition, tight integration between EPR systems, mobile technology and whiteboard systems may create situations and ripple effects where a system error in one place causes unexpected results in other connected systems. When the EPR stop working, the whiteboards and mobiles stops working too. Kalnes have established back-up routines with manual follow up when this happens. The problem is that this creates double registration routines for as long as the system is unavailable, and that information has to be registered back into the respective systems when the error is corrected. Tight coupling may be partly reduced by having an RPM (resource and process management) interface between mobile and whiteboard technology system and the EPR system. This interface enables the access to a separate database when the EPR system fails and consequently gives a looser coupling between the process technology and the EPR system.

\section{Analyzes: Challenges and outcomes of process innovation}

Digitalization of manual processes and resources provides opportunities for a better overview of organizational behavior. Establishing arenas to discuss the result of digitalization allows early identification of the positive and negative consequences of digitalization, and making decisions that can strengthen or mitigate these consequences.

Process innovation is challenging in that it favors the horizontal and deemphasize the functional perspective. Understanding the concrete consequences of 
digitalizing coordinative paths is thus important in order to balance and control innovation efforts. In order to analyze our case we use insights from [1]. They categorize their findings into negative outcomes, which (may) turn into vicious circles, and positive outcomes that turns into increasing returns and virtuous circles (figure 3 ). Table 2 outlines our findings.

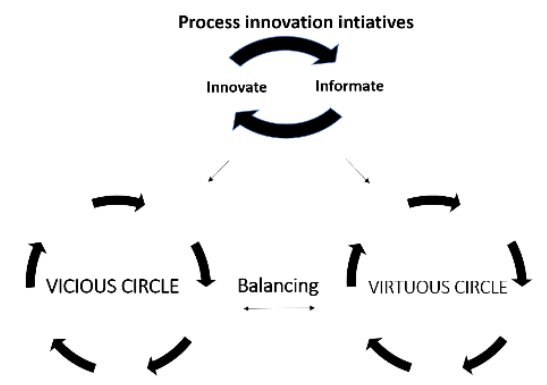

Figure 3: Possible outcome of process innovation

Table 2: Vicious and virtuous effects

\begin{tabular}{|c|c|}
\hline INNOVATE & INFORMATE \\
\hline $\begin{array}{l}\text { Identify bottlenecks and } \\
\text { streamline manual } \\
\text { processes with IT. }\end{array}$ & $\begin{array}{l}\text { Make information visible and } \\
\text { actionable. }\end{array}$ \\
\hline $\begin{array}{l}\text { Implement cross-sectional } \\
\text { coordinative IT. }\end{array}$ & $\begin{array}{l}\text { Distributed information } \\
\text { access. }\end{array}$ \\
\hline $\begin{array}{l}\text { Integrate modules through } \\
\text { a common interface. }\end{array}$ & $\begin{array}{l}\text { Sets in motion a series of re- } \\
\text { configuration and redesign } \\
\text { possibilities. }\end{array}$ \\
\hline \multicolumn{2}{|c|}{ MAY LEAD TO } \\
\hline VICIOUS & $\begin{array}{l}\text { VIRTUOUS } \\
\end{array}$ \\
\hline $\begin{array}{l}\text { Tight coupling between } \\
\text { systems creates challenges } \\
\text { when one of the systems } \\
\text { collapse } \\
\text { Unclear relations between } \\
\text { where data is registered } \\
\text { and where they are stored } \\
\text { Universal resource } \\
\text { management creates } \\
\text { competing priorities } \\
\text { between wards and may } \\
\text { reduce local autonomy over } \\
\text { resources }\end{array}$ & $\begin{array}{l}\text { Coordinators and cleaners can } \\
\text { analyze the result of and } \\
\text { improve their work. } \\
\text { Improved interplay between } \\
\text { coordinators and clinicians } \\
\text { Common "flow arenas" for } \\
\text { addressing workflow } \\
\text { challenges } \\
\text { Common access to cross- } \\
\text { sectional resources improves } \\
\text { capacity utilization } \\
\text { Increased insights in end-to- } \\
\text { end processes and a process- } \\
\text { oriented organization }\end{array}$ \\
\hline
\end{tabular}

Innovate, is about digitalizing manual processes or make singular processes earlier digitalized interact. Digitalization may improve efficiency by removing bottlenecks and streamline manual processes. This use of ICTs potential to enable cross-sectional coordination is also enabled by interfaces and modules positioned in the technical architecture which gives access to information across system domains. The integration of the two systems with the personal administration system GAT, gives a rich repository of information available for making and extending functionality.

Informate is the effect of digitalization when certain conditions are met. Information is made visible and actionable when whiteboard and mobile technology is implemented in a way that is aligned with horizontal coordinative processes. Information made visible and actionable across hospital departments and wards activates a set of re-configuration possibilities. By actionable we mean that the information can be acted upon digitally, by clicking, drag-and-drop and similar, based on decisions taken. The innovate - informate interaction gives possibility to re-configure processes and to investigate the effect this re-configuration have on horizontal and functional processes. It shortens the loop between acknowledged shortcoming and improvement, but it thereby also threatens the stability of existing ways of doing things. It may both lead to vicious and virtuous outcomes.

Vicious circles may emerge during digitalization and creation of coordinative paths. Tight coupling between heavyweight and lightweight IT can cause vicious circles. When the coupling causes all systems to go down when one system goes down, manual followup routines is needed as a backup. The organizational information acquired during system collapse later has to be registered back into the respective systems, introducing possible challenges related to accuracy and precision. A second challenge may arise when users used to relate to one particular system must relate to several systems governed by other clinical domains. This may lead to hesitation and delayed registration of important information. A third vicious effect leading to negative circular spirals may be caused by the universal availability of resources. Some resources like special rooms, equipment or humans may be better utilized locally.

Virtuous circles on the other hand may arise when changes have positive outcome. At Kalnes coordinators and cleaners ability to perform self-management have improved because they have gained better tools for reflecting on performance. Further, we observed that although some of the doctors are critical towards the whiteboard system, they actively participate in some of the arenas where horizontal flow coordination is addressed. Improved process flow may be in their interest. The "flow-arenas" also create a certain motivation in improving capacity utilization. The transparency of organizational performance seems to give an improved understanding of cross-sectional challenges and triggers activities and solutions to address them. Kalnes is designed to enable process flow also in that the health wards are designed equally. This 
enables flexibility and universal availability of resources. The technological portfolio is partly modularized. The RPS engine gives a looser coupling between the outside and the inside of the organizational system, protecting its internal logic. It may operate independently of the regional infrastructure if needed. The increased informating ability also makes it easier to provide counter-strategies when needed, in that side effects are identified relatively early.

\section{Discussion}

We return to our research question: What are the challenges and the outcomes of using lightweight IT in process innovation initiatives at a general hospital? Digitalization is a key factor in process innovation, which is about translating information into action by removing manual work and bottlenecks between the source and the registration [30]. Informate is the effect of the digitization of manual processes or the linking of already digital processes causing a common outcome. The interaction between innovation and informating leads to outcomes which can be referred to as either virtuous or vicious. While [1] are interested in knowledge management strategies and the outcome of continuous efforts to digitalize knowledge, we are looking at the relation between coordination practices and accessibility to cross-sectional information in process innovation initiatives. A central premise for the universal access to process flow information we find, is the interplay between heavy and lightweight technologies. This interplay does also enable optimization of vertical and horizontal processes. The shared division of labor [27] allow organizational actors and workgroups with different epistemologies to collaborate through "rich connections" [1]. The premise for this is however that the mapping between technology and practice is carefully balanced and that side effects are taken care of.

We give two contributions. First, we draw on literature on digital innovation [8, 20, 21, 23, 25] to investigate how lightweight technology strengthens path creation initiatives dealing with optimization of horizontal flow. Lightweight technology and the knowledge regimes attached to it are concerned with continuous improvement, and this requires dynamic and flexible follow-up from the supplier. "Imatis have understood that the development is happening here and now, not in 2 or 3 years" as one internal project leader makes clear. A central aspect of lightweight technology is its informating ability. Huge whiteboards displaying patient information are used by a knowledge regime that operates around patient flow processes. The actors are equipped with mobile technology to improve communication across wards. It is earlier claimed that whiteboards strengthens communication and commitment [26] and optimize information management [28]. These studies investigate processes within isolated departments. Our work demonstrates the process innovation capacity of lightweight technology in sharing, visualizing and redistributing information enabling horizontal process improvement across departments. This informating potential enables changed control paradigms [20], through distributed organization [21] in that the procedural distance between action and the effect of this action is reduced. This gives local actors improved insight into horizontal processes. The increasing redesign flexibility enables Kalnes to continually monitor and improve the innovation initiatives. The coordinative actors are engaged in technological development and become key players in process innovation in that they participate and monitor directly the outcome of the interventions.

The second contribution is insight into efforts related to digitalization of processes, and the effect of these. Digitalization processes intervene in organizational inertia and triggers organizational tension. Silo systems, clinical regimes, work processes, routines and regulations which have been more or less aligned is reenacted, brought into life, and has to be aligned once again. Accordingly, the functional and the horizontal efforts must be balanced. By using the framework of vicious and virtuous cycle [1] we explicitly look at how innovation initiatives with lightweight technologies, backed by heavyweight technology, informate organizational processes and enables efficiency improvements. By doing this we also shed light on some of the challenges and the risks of creating coordinative paths.

In conclusion, digitalization is challenging, cumbersome and laborious, but necessary in order to improve organizational performance and capacity utilization. Digitalization of manual processes and routines prepares the fundament for two important improvements. The organization may faster adapt to ever-changing societal requirements. Moreover, the organization are better able to monitor their own performance. If hasty changes have been implemented, the detection of the negative outcomes of these changes can be done relatively fast, the organization may adjust the intervention and try again. If the change is successful, a new horizontal path has been created and might be further improved.

\section{References}

[1] R. Garud, and A. Kumaraswamy, "Vicious and Virtuous Circles in the Management of Knowledge: The Case of INFOSYS Technologies.” MIS Quarterly, vol. 29, p. 9-33, 2005.

[2] Mintzberg, H, Structure in fives: Designing effective 
organizations. Englewood Cliffs, N.J: Prentice-Hall, 1983 [3] Salazar, A., Ortiga, B., Escarrabill, J., and Corbella, X, "Emergency department complaints: A 12-year study in a University hospital." Annals of Emergency Medicine, 2004

[4] Norwegian Ministry of Health. Prep 125. 2015

[5] Helsedirektoratet 2016 Coordination reform https://helsedirektoratet.no/samhandlingsreformen

[6] Davenport, T, Process innovation: reengineering work through information technology, Harvard Business Press, 1993

[7] W.A.M, Van Lent, E. M. Sanders, and W. H. Van Harten, "Exploring improvements in patient logistics in Dutch hospitals with a survey." BMC Health Services Research, 12, 232-240, 2012.

[8] B. Bygstad, "Generative innovation: A Comparison of Lightweight and Heavyweight IT," Journal of Information Technology, 1-14, 2016

[9] M. Hertzum, and Simonsen J, "Work-practice changes associated with an electronic emergency department whiteboard," Health Informatics Journal, 19 (1) 46-60, 2013 [10] D. J. France, S. Levin, R. Hemphill, K. Chen, D. Rickard, R. Makowski, I. Jones, and D. Aronsky, "Emergency physicians' behaviors and workload in the presence of an electronic whiteboard," International Journal of Medical Informatics 74, 827-837, 2005

[11] SINTEF, Gevinstanalyse av IMATIS i Bærum kommune, https://www.sintef.no/publikasjoner/publikasjon/ pubid=SINTEF+A27754 2016

[12] F. Bannister, "Dismantling the silos: extracting new value from IT investments in public administration." Information Systems Journal, 11(1):65-84, 2001

[13] H. Bowman, H. van Houtum, M. Janssen, and G. Versteeg, "Business Architectures in the Public Sector Experiences from Practice." Communications of the Association for Information Systems, Vol. 29, 2011. [14] E. Monteiro, "Scaling Information Infrastructure: The Case of Next-Generation IP in the Internet", The Information Society, 14:3, 229-245, 1998.

[15] S. Devaraj, T. T. Ow, and R. Kohli, "Examining the Impact of Information Technology and Patient Flow on Healthcare Performance: A Theory of Swift and Even Flow (TSEF) Perspective". Journal of Operations Management 31, 4, 2013

[16] B. Bygstad, and B. E. Munkvold, "Exploring the role of informants in Interpretive Case Studies Research in IS", Journal of Information Technology, p. 32-45, 2011

[17] T. Rotter, L. Kinsman, E. L. James, A. Machotta, H. Gothe, J. Willis, P. Snow, and J. Kugler, "Clinical pathways: effects on professional practice, patient outcomes, length of stay and hospital costs," Cochrane Database, 2010 [18] J. De Vries, and R. Huijsman, "Supply chain management in health services: an overview", Supply Chain Management: An International Journal, Vol. 16 Iss: 3, pp.159 $-165,2011$.
[19] L. Mathiassen, and P. A. Nielsen, "Engaged Scholarship in IS Research- The Scandinavian Case," Scandinavian Journal of Information Systems, Vol. 20, No. 2, 3-20, 2008. [20] D. Tilson, K. Lyytinen, and C. Sørensen, "Research Commentary, digital infrastructures: the missing IS research agenda.” Information Systems Research, 21, 748-759, 2010. [21] Y. Yoo, O. Henfridsson, and K. Lyytinen, "Research Commentary-The New Organizing Logic of Digital Innovation: An Agenda for Information Systems Research." Information Systems Research, 21(4):724-735, 2010.

[22] R. Garud, A. Kumaraswamy, and P. Karnøe, "Path dependence or path creation," Journal of Management Studies, Volume 47, Issue 4 June 2010 p. 760-774. [23] O. Henfridsson, L. Mathiassen, and F. Svahn, "Managing technological change in the digital age: the role Of architectural frames. Journal of Information Technology, 29, 27-43, 2014.

[24] E. Øvrelid, and B. Bygstad, "Extending e-health infrastructures with lightweight IT.” In Lecture Notes in Business Information Processing. 1865-1348. 2016, 43-56. [25] B. Bygstad, O. Hanseth, A. Siebenherz, and E. Øvrelid, "Process innovation meets digital infrastructure in a high tech hospital," 25th European Conference on Information Systems (ECIS) Guimarães, Portugal, 2017

[26] M. Hertzum, and J. Simonsen, "Visual overview, oral detail: The use of an emergency-department whiteboard," Int. J. Human-Computer Studies, 2015, 82, 21-30.

[27] I. Nonaka, and H. Takeuchi, The Knowledge-Creating Company, Oxford University Press, New York, 1995

[28] D. Aronsky, I. Jones, K. Lanaghan, and C. Slovis, "Supporting patient care in the emergency department with a computerized whiteboard system." J.Am.Med. Inf.

Assoc.15(2),184-194. 2008

[29] H. J. Wong, M. Caesar, S. Bandali, J. Agnew, and H. Abrams, "Electronic inpatient whiteboards: improving multidisciplinary communication and coordination of care." Int.J.Med.Inf, 78 (4), 239-247, 2009.

[30] M. Hammer, "Reengineering work: don't automate, obliterate." Harvard Business review, 1990

[31] S. Zuboff, In the age of the smart machine, Basic Books, 1988, New York

[32] R. Garud and P. Karnøe, "Path Creation as a process of Mindful Deviation," in Path Dependence or Path Creation?, Erlbaum, New Jersey, p. 1-40, 2001.

[33] G. Ellingsen, and E. Monteiro, "The slight surprise of Integration,” In: Sørensen C., Yoo Y., Lyytinen K., DeGross J.I. (eds) Designing Ubiquitous Information Environments: Socio-Technical Issues and Challenges, vol 185. Springer, Boston, MA, 261-274, 2005.

[34] M. Masuch, "Vicious Circles in Organizations," Administrative Science Quarterly (30:1), pp. 14-33, 1985. [35] Gerring, J., Case Study Research: Principles and Practices, Cambridge University Press, 2006 